\title{
A mathematician extraordinary James Joseph Sylvester (1814-1897)
}

\section{TONY CRILLY}

From the first floor library window of the Athenaeum Club a lone figure could be observed circumnavigating the ornamental ponds in St James' Park. He was dressed in a black frock-coat, with a gold fob dangling from his waistcoat and as he walked along, the fob glinted in the early summer sunshine.

As he passed over the bridge dividing the two ponds his speed increased perceptibly. The mincing steps became more purposeful and he changed direction towards the front entrance of the club for the

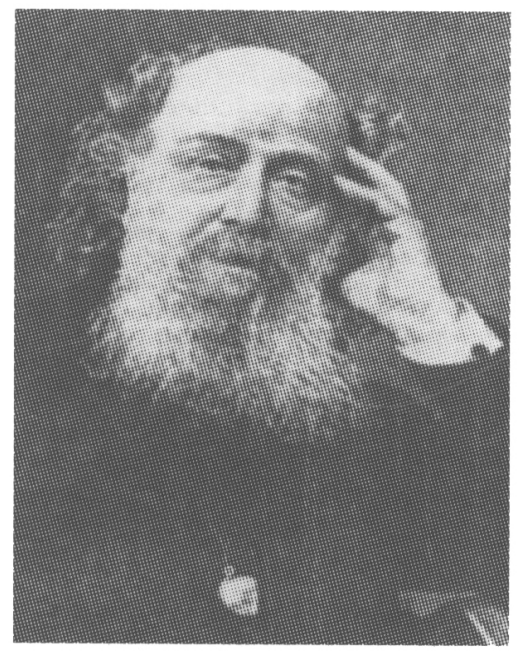
literary and scientific. At the top of the curving staircase James Joseph Sylvester arrived at the reading room, breathless and excited. He paced across the floor, sat down awkwardly at a corner desk, and seized a pen. 'Dear Cayley', he wrote. 'I believe I have just proved Gordan's theorem and it is so ridiculously simple. I have found the key which opens the lock and, by a side passage, have entered into a chamber where all was laid out before me. I shall send the proof by the afternoon post.' The words were written at speed, and, ending the tale of his latest discovery, Sylvester dipped his quill once more, wrote out Cayley's address on the envelope, and placed the letter in the members' tray for posting. As an afterthought he retrieved it, checked the legibility of the address and scratched on the back of the envelope: 'How wonderful it is to have solved this riddle by ordinary algebra!'.

James Joseph turned on his heels and walked into the drawing room to relate the glad tidings to a member. Few of the elderly habitués of the Athenaeum would have had any interest in the higher reaches of algebra and almost surely none would have heard of the German mathematician Paul Gordan. This obvious fact did not deter Sylvester as he spied a suitable target slumbering in the corner beneath the clock.

In the evening there was no mistaking the contentment on Sylvester's face as he sat at dinner. That he dined alone did not diminish his obvious well-being. The cavernous members' dining room with its muffled conversations and clinking table cutlery was where he felt most at home. He missed the Athenaeum acutely while living in America. The servants 
moved noiselessly between the tables and, with due deference, enquired into the comfort of their social superiors. On this evening, with the achievement of the day, Sylvester was truly fulfilled.

Sylvester was an ageing Victorian gentleman with a curious niche in the scientific community of London of which he had been a part for some forty years. Associates admired his brilliance, tolerated his idiosyncrasies but were wary of his taste for priority disputes. To this audience he repeatedly expressed the view that research in mathematics shared common features with research in science. Experimentation was a key feature in both endeavours. It was a point the scientists did not fully appreciate yet they treated him kindly and for his enthusiasm one said he did not require 'a hacked edge'. On the annual visit to England this summer, he could reflect on his trail-blazing role at Johns Hopkins University in Baltimore where he had been for the last seven years. Sylvester had done well in this latest chapter of his hectic career.

From his Jewish background in the East End of London, Sylvester's youthful genius had won him a place at St John's College, Cambridge. He continued his upward spiral: professor at University College when twentytwo years of age and an FRS shortly afterwards. A brief but eventful period was spent at the University of Virginia before coming home to work as an actuary in the City of London. His mathematical researches continued, interrupted occasionally by periods of the depression to which he was prone. He met his great friend Arthur Cayley and the two engaged in research together during the 1850s and thereafter. After fourteen years at the Royal Military College at Woolwich he took early retirement. In the mid-1870s Johns Hopkins was looking for European staff and Sylvester was willing to take the chance of another sojourn in the United States.

Sitting in the Athenaeum dining room, approaching seventy years of age, Sylvester looked forward. He was not one to dwell on the past but was still impatient to make new discoveries. He thought of his Johns Hopkins research school hard at work in his absence. They would no doubt be busy on the latest piece of calculation, work which demanded the closest attention and accuracy. Stretched before them would be large sheets of paper with vertical columns and hunched over their desks they would ink in the latest primary invariant.. For the quintic polynomial there are twenty-three primary invariants, as had been found by Gordan, but Sylvester had his eye on higher order polynomials.

The English method in invariant theory was to write down a generating function for enumerating invariants and, by combing through their huge expansions, to look for the clues which would reveal the primary invariants. The higher the order of the polynomial the more extensive the generating

For the quadratic $a x^{2}+b x+c$ there is only one invariant, the discriminant $b^{2}-4 a c$. The general objective for invariant theory involved finding a basic set of irreducible invariants (and expressions called covariants) for homogeneous polynomials which were called by Cayley binary quantics. I refer to this problem as one of finding the primary invariants of a polynomial. 
function and the process more laborious. The sifting of the generating function, or, as Sylvester gloriously called it, the method of Tamisage, was beyond the capabilities of one person. His Baltimore team of human computers was compliant under his direction and Sylvester wielded the baton with intensity.

To have proved Gordan's theorem would surely stun the mathematical world - a world which was not easily impressed. Sylvester's proof had come at the end of fifteen years struggle and it was a piquant moment when the linchpin had been inserted into the argument while perambulating in St James' Park. It was a vindication of his and Cayley's approach to invariant theory. Neither he nor his friend believed in the abstract calculus invented by the German mathematicians despite its undeniable power. They believed in straightforward algebra. Theirs was not a method of relentless logic and the manipulations of an abstract calculus but one of sure-footed insight and real algebra.

Sylvester had felt this confident mood many times before but never before proving a result of such magnitude. In the 1850 s Cayley had announced, in irretrievable print, that the number of primary invariants for some polynomials was infinite. A decade later, in a dramatic announcement, Paul Gordan had announced the contrary: for polynomials of any order, the number was finite. This left the way open to consider 'Gordan's theorem' for polynomials of an arbitrary number of variables. Yet Gordan's more limited result had established a watershed. It was another sign of the superiority of German scholarship and the advance guard in England, who summoned the nation by the slogan to go out and 'Germanise the universities', would have received an added fillip. But now, in the early 1880 s, Sylvester had surely redressed the balance. At one stroke national honour was re-established and into the bargain Sylvester had claimed his right to be regarded as a European mathematician of the front rank.

No wonder that Sylvester went to his bedroom that night in an elated mood. He closed his eyes and was quickly asleep. He slept deeply but sometime after midnight, as he turned in the large four-poster, a noise from the adjacent dressing-room disturbed his slumbers. In the dressing-room, which now seemed large, a social gathering seemed to be in full swing. As he blinked in the light, he recognised the faces of old acquaintances and mathematical colleagues. Charles Hermite was there and so too were Camille Jordan and Felix Klein. Behind them a knot of German mathematicians were engaged in a vigorous conversation. Was it not Gordan himself in the centre? A whole galaxy of European mathematicians were present. In a white flowing robe a youthful Alfred Clebsch was detached from the others, the Wunderkind of the German mathematicians.

As Sylvester surveyed the scene a muffled gong sounded and the room fell silent. Hermite rose to his feet. 'Gentlemen,' he said in a serious tone 'we are here to honour a great mathematician. A man who has made an indelible mark on our subject. A man who by his ingenuity has proved the 
theorem after which we have all been striving. I give you ..., and here he paused, just long enough for Sylvester to wonder about the reality of it all. Hermite continued his toast: 'I give you James Joseph Sylvester.' Sylvester glanced around and they were all clapping; they were all toasting him. And there was Gordan acknowledging him as an equal.

Outside in Westminster, Big Ben tolled three o'clock. Sylvester heard the peal and turned over. The hubbub around him was evaporating. Hermite, who had filled the scene moments before, grew smaller. The room of mathematicians gradually faded and disappeared through the ornate Victorian wood panelling. The applause receded until it became indistinguishable from the gentle rain tapping against the Athenaeum window.

The dressing-room was transformed into a long narrow room where, in the distance, a small figure was sitting at a tall desk scribbling at speed. Pages were being filled, the completed leaves falling to the floor. Calculations were being piled on more calculations but it appeared they were not going well. The long generating function expansions lay before him but they failed to give the correct result. As Sylvester moved closer he instantly recognised the anxious face.

In the distance, Big Ben chimed the quarter-hour. 'Cayley would see the mistake', the figure murmured. It was knife-edge mathematics. One arithmetical slip and the whole edifice would be threatened. The one difficulty which Sylvester failed to grasp concerned the linear relations which might exist between invariants. The Fundamental Postulate, a pragmatic assumption which allowed only a limited number of relations to exist, was at bottom only an assumption. It was based on empirical results in the case of polynomials of small order but Sylvester had always felt confident of its truth in general. It was consistent with established theorems but it had no status beyond surmise. It enabled him to glide over difficulties and perhaps this had unconsciously persuaded him. He began to have misgivings.

Outside the bedroom the rain subsided, and, as the dawn broke, shafts of light shone through gaps in the heavy velvet curtains. Sylvester dozed uncomfortably. Coming down to breakfast he was agitated and he sat at table in a morose mood. This was not the Sylvester of twelve hours before. Could the Fundamental Postulate be false? He had likened the primary invariants and their linear relations to electrical positive and negative charges and the Postulate was analogous to the physical law whereby "electricities of the two kinds cannot coexist at the same time at the same point of the body'. Was this too fanciful? Sylvester had doubts and likely consequences occupied his mind. His membership of the premier division of mathematicians might be cruelly taken away, if indeed he had been admitted in the first place.

After breakfast, Sylvester slipped out of the Athenaeum and retraced his steps of the previous day. Around the ponds of St James' Park he went, deep in thought. People stared but he was oblivious of their attention. His pace 
only slowed as he ascended the staircase of the club and entered the reading room. He sat down at a writing bureau and addressed a note. 'Dear Cayley,' he wrote once more, 'My proof of yesterday was a delusion. There is a mistake somewhere.' He brightened a little as he continued: 'But all is not lost. I am morally certain as anything that the Postulate could be true. I wish you would tell me if I am under an illusion in this Gordanic business.'

In the weeks and months which followed, Sylvester never gave up his quest to prove Gordan's theorem though he never succeeded. He was reluctant to abandon the 'very reasonable' Fundamental Postulate which he tried to salvage from the wreckage. It held true for some polynomials but there were undeniably cases where it failed, as he and other mathematicians subsequently discovered.

A few years later a young German mathematician, David Hilbert, stole the limelight when it came to the proof of Gordan's theorem for polynomials of any order and any number of variables. His successful method was quite new and the work was outside Sylvester's ken. Sylvester was bound up with the algorithmic side of invariant theory while the abstract existence proof which Hilbert offered was quite foreign to him. As Sylvester grew into old age he had a brief encounter with a parallel theory of reciprocants not unlike invariant theory. He invited Cayley to join him but they were without the time or energy to begin again on the long road of invariant theory.

Sylvester was appointed professor at Oxford for the last chapter of his career. He breathed new inspiration into mathematics at the university at a time when it was in a moribund state. After a lifetime 'fighting the world', as he used to say, he found Oxford a haven in his old age. In February 1892 he became unwell. He suffered cataracts in his eyes and periods of tiring depression. He left Oxford to retire to an apartment in Mayfair in a backwater of London's West End. In his last years he turned to number theory. It required little in the way of algebraic theory but a good measure of ingenuity and skill, both qualities which Sylvester could still summon.

James Joseph Sylvester infused his work with poetry, literature and philosophy and perhaps his intense feeling for mathematics will be long remembered when his mathematical contributions have faded on the page. He decorated the scientific and social milieu of the nineteenth century and died two years after his friend Cayley, on the ides of March 1897.

TONY CRILLY Middlesex University, Queensway, Enfield, Middlesex EN3 4SF

Mixed 'mathemetaphors'

The Government has long backed 'variable geometry', under which member states of the European Union would be allowed to vary the speed at which they took part in further integration.

From the Daily Telegraph, Saturday, 18 May 1996, gleaned by Malcolm A. Perella. 